\title{
Novel Fluorescent Probes for Amyloidd Detection
}

\author{
DOI: 10.17691/stm2017.9.2.11 \\ Received December 7, 2015
}

S.P. Sapozhnikov, MD, DSc, Head of the Department of Medical Biology with the Course of Microbiology

and Virology";

P.B. Karyshev, Laboratory Assistant, Department of Medical Biology with the Course of Microbiology and Virology';

A.I. Sheptukhina, PhD Student, Faculty of General Medicine";

O.V. Nikolayeva, Resident, Faculty of General Medicine';

A.A. Avruyskaya, PhD Student, Department of Biology and Chemestry2;

Y.N. Mitrasov, DSc, Professor, Department of Biology and Chemestry2;

V.A. Kozlov, MD, PhD, DSc, Professor, Department of Medical Biology with the Course of Microbiology and Virology ${ }^{1}$

${ }^{1}$ I.N. Ulianov Chuvash State University, 15 Moskovsky Prospect, Cheboksary, 428015, Russian Federation;

${ }^{2}$ I.Y. Yakovlev Chuvash State Pedagogical University, 38 Karl Marx St., Cheboksary, 428000, Russian Federation

Based on the notions of supramolecular nonenzymatic interaction of amyloid with known fluorescent probes (thioflavin T and Congo red) a search for the substances, which may be perspective as fluorescent probes selective to amyloid in the line of 4-N-aryl-3,5-dioxo-1formyl-10-oxa-4-azatricyclo[5.2.11.7.02.6]dec-8-ene derivatives has been undertaken.

Dry crystals of the chosen substances having the structure of the molecular rotor similar to thioflavin T emitted light in the visible range of $421.0-435.5 \mathrm{~nm}$, when excited by ultraviolet. Dissolution of the substances in $96^{\circ}$ ethanol extinguishes fluorescence. Wateralcohol solutions of these substances $\left(0.75 \%\right.$; water:ethanol $\left.96^{\circ}=1: 1, \mathrm{pH}>7\right)$ also did not emitted the light (beyond the sensitivity of photomultiplier FEU-39). Treating with alcohol solutions of the tested preparations the depersonalized deparaffinated, preliminarily stained with hematoxylin, human kidney sections with clinically and histologically proved kidney amyloidosis was not accompanied by a marked fluorescence. Staining of the sections of the same kidney with water-alcohol alkalized solution of these preparations after imbedding into the non-fluorescent transparent medium was accompanied by luminescence of all kidney structures in the visible range at a wavelength of $534 \mathrm{~nm}$ with a more intensive luminescence of amyloid deposits than cellular structures.

Conclusion. The result obtained opens good perspectives of using the tested substances as novel fluorophores for detecting amyloid.

Key words: amyloid; fluorescent probes; molecular motors; amyloid kidney damage; thioflavin; azatricyclo-dec-ene.

Owing to the works of Jean-Marie Lehn, the established concepts of the possibility of large organic molecules to interact with each other as macroobjects without strong chemical bonds forming actually a new substance, a supramolecular structure, served as a basis for forming a new judgement about the structure and interaction of organic compounds. The fact that parts of the molecules of some organic substances of nonprotein nature can directionally rotate relative to each other due to the disruption of $\pi$-conjugated bonds inside the molecule under the action of the external energy [1], serving as "a molecule rotor", is one of the relatively recently found types of supramolecular interaction. Such molecular behavior would remain a curious molecular incident, if it were not a property of rotors to re-emit the accumulated potential energy in the visible light range during rotation slowdown by the medium molecular environment. Incorporation of the molecular motor, if it in itself is a fluorophore, in some supramolecular structure is accompanied by a bathochromic shift. That is, the spectrum of the substance emission is displaced to the red side, which is the evidence of incorporation.
This property allows identification of the medium to which such a fluorophore is specifically bound: if there is binding, there is fluorescence; if there is no binding, no fluorescence occurs. The opposite statement is true: if some substance binding to such medium starts to fluoresce more intensively than without binding, and a bathochromic effect is observed, it is a molecular rotor.

Thioflavin, a specific fluorescent amyloid ligand, is one of such substances. A low quantum yield of thioflavin fluorescence, induced by ultraviolet light, in low-viscosity media is supposed to be due to the rotation of benzothiasole and N,N-dimethylamine rings relative to each other. When thioflavin is incorporated into amyloid structure, an essential increase of quantum yield takes place [1, 2]. While examining the interaction of thioflavin with amyloid, it was established to destroy amyloid, at least in vitro [3]. In this connection, a search for substances perspective to be used as a tool for amyloid diagnosis [4] as well as medicinal agents to treat amyloidosis [5] was started among thioflavin derivatives, as no effective methods of diagnosis, prevention, and therapy of this disease have been developed until now.

For contacts: Vadim A. Kozlov, e-mail: pooh12@yandex.ru 
Moreover, predictors enabling the physicians to define the groups of patients, in whom the course of the basic disease will be complicated by amyloidosis, have not been found.

Thioflavin is not produced in the Russian Federation and is delivered from other countries. In compliance with the technical passport supplied by the manufacturer (Santa Cruz Biotechnology, USA) together with the preparation, $\mathrm{LD}_{50}$ of thioflavin taken by mice perorally is $151 \mathrm{mg} / \mathrm{kg}$ of body mass. According to GOST 12.1.00776 and SanPiN 2.1.4.1074-01 it is referred to toxicity class III, moderately hazardous substances (the range of $151-5,000 \mathrm{mg} / \mathrm{kg}$ of body mass). Considering the range of variations, this preparation can get to toxicity class II, which excludes its application in medicine. This conclusion was confirmed by us in preliminary studies of thioflavin toxicity [6], in which subcutaneous injection of the preparation to mice at the dose of $50 \mathrm{mg} / \mathrm{kg}$ caused $100 \%$ lethality. For this reason and because of a limited quantity of this expensive reagent, it was decided to use it as a postmortem stain without specifying its toxicity for parenteral introduction. As antiamyloid effect of thioflavin is likely to be caused by its supramolecular interaction with amyloid [3], its pharmacological efficacy must be in direct quantitative relation to the injected dose. On this account the application of thioflavin or its close derivatives as pharmaceutical agents seems to be unpromising.

Nevertheless, it may be supposed that there exist substances close in their chemical structure to thioflavin, not being derivatives of benzothiasole, but having the properties similar to molecular motors, which can be used as fluorophores for amyloid detection.

The aim of the investigation was to search for the amyloid-selective markers among the substances having the chemical structure similar to thioflavin.

Materials and Methods. Investigators of the Department of Biology and Chemistry from I.Y. Yakovlev Chuvash State Pedagogical University and the Medical Faculty of I.N. Ulianov Chuvash State University have designed a molecular rotor based on the structure of azatricyclo-dec-ene completed by the synthesis of 4-N-aryl-3,5-dioxo-1-formyl-10-oxa4-azatricyclo[5.2.11.7.02.6]dec-8-ene (formula 1a-e) derivatives to be used as a perspective amyloid-selective fluorescent probes:

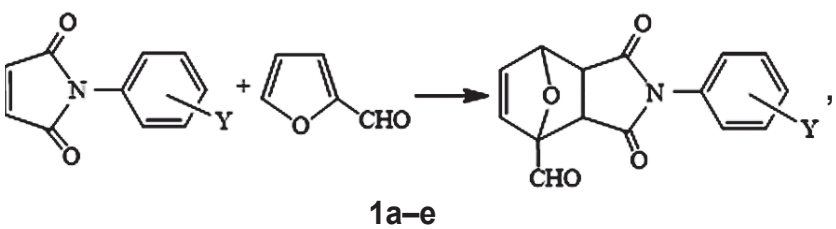

where $\mathrm{Y}=2-\mathrm{NO}_{2}(\mathrm{a}), 3-\mathrm{NO}_{2}(\mathrm{~b}), 4-\mathrm{NO}_{2}(\mathrm{c}), 3-$ $\mathrm{COOH}(\mathrm{d}), 4-\mathrm{COOH}(\mathrm{e})$.

The tested substances (1a-e) were synthetized by the interaction of easily available $\mathrm{N}$-aryl-2,5dihydropyrrol-2,5-diones with furan-2-carbaldehyde in the equimolar reagent ratio at room temperature $[6,7]$. Absolute 1,4-dioxan was used as a solvent. Purity of the synthetized products was controlled by the data of a thin-layer chromatography, the structure was verified by IR, ${ }^{1} \mathrm{H}$ NMR spectroscopy. Compounds (1a-e) are crystal substances of a light yellow or orange color. Their constants and elemental analysis data are presented in Table 1.

The experiments with amyloid deposit staining were conducted on depersonalized $5 \mu \mathrm{m}$ paraffin sections of human kidneys provided by the Republic Bureau of Forensic Medical Examination (Cheboksary, Russia), where clinically established diagnosis of amyloidosis was pathohistologically confirmed. Three series of deparaffinized sections were preliminarily stained with hematoxylin. The control (first) series was stained with thioflavin T according to Vassar [8].

The second section series, after being stained with hematoxylin, was additionally treated for $3 \mathrm{~min}$ with alcoholic solutions of tested preparations (1a-e), the third series was treated with water-alcohol solutions. $1.5 \%$ alcoholic solutions were prepared by dissolving a weighed quantity of preparations in $96^{\circ}$ alcohols at room temperature, water-alcohol solutions were

Table 1

Yields, constants and data of elemental analysis

\begin{tabular}{|c|c|c|c|c|c|c|}
\hline \multirow{3}{*}{$\begin{array}{c}\text { Compound number } \\
\text { of substances }\end{array}$} & \multirow{3}{*}{$\begin{array}{c}\text { Yield } \\
\text { of substances } \\
(\%)\end{array}$} & \multirow{3}{*}{$\begin{array}{c}\text { Melting } \\
\text { temperature } \\
\left({ }^{\circ} \mathrm{C}\right)\end{array}$} & \multicolumn{3}{|c|}{ Found $(\%)$} & \multirow{3}{*}{$\begin{array}{l}\text { Brutto } \\
\text { formula }\end{array}$} \\
\hline & & & \multicolumn{3}{|c|}{ Calculated (\%) } & \\
\hline & & & C & $\mathrm{H}$ & $\mathrm{N}$ & \\
\hline \multirow{4}{*}{ 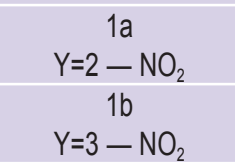 } & \multirow{2}{*}{62} & \multirow{2}{*}{$95-98$} & 57.32 & 3.18 & 8.91 & \multirow{2}{*}{ C15H10N2O6 } \\
\hline & & & 57.40 & 3.24 & 9.01 & \\
\hline & \multirow{2}{*}{40} & \multirow{2}{*}{ 201-203 } & 57.32 & 3.18 & 8.91 & \multirow{2}{*}{ C15H10N2O6 } \\
\hline & & & 57.42 & 3.27 & 9.02 & \\
\hline $1 c$ & \multirow{2}{*}{51} & \multirow{2}{*}{ 189-191 } & 57.32 & 3.18 & 8.91 & \multirow{2}{*}{$\mathrm{C} 15 \mathrm{H} 10 \mathrm{~N} 2 \mathrm{O} 6$} \\
\hline $\mathrm{Y}=4-\mathrm{NO}_{2}$ & & & 57.43 & 3.26 & 8.99 & \\
\hline $1 d$ & \multirow{2}{*}{50} & \multirow{2}{*}{$215-217$} & 61.34 & 3.51 & 4.47 & \multirow{2}{*}{ C16H11NO6 } \\
\hline$Y=3-\mathrm{COOH}$ & & & 61.45 & 3.63 & 4.59 & \\
\hline $1 e$ & \multirow{2}{*}{54} & \multirow{2}{*}{$223-225$} & 61.34 & 3.51 & 4.47 & \multirow{2}{*}{ C16H11NO6 } \\
\hline$Y=4-\mathrm{COOH}$ & & & 61.45 & 3.59 & 4.55 & \\
\hline
\end{tabular}


prepared by dilution of the obtained alcohol solution with $1 \%$ water solution of $\mathrm{NaOH} 1: 1$ by volume $(\mathrm{pH}>7)$, the final concentration of preparations amounted to $0.75 \%$. After staining, the sections were washed with water, dehydrated, and embedded in polystyrene.

The sections were examined under Lumam-4 microscope (Lomo, Russia). Fluorometry was performed with the help of FMEL-1A nozzle (Lumo, Russia), barrier emission filter ZhS18 (yellow lens), $I_{\text {excit. }}=410 \mathrm{~nm}$, light filters FS (violet glass), BS (white glass), SZS (blue-green glass). Electrical parameters of all measurements were similar: $900 \mathrm{~V}$ input voltage, $10^{6} \mathrm{Ohm}$ amplifier resistance. A 0.5 probe was installed in the attachment. FEU-39 photoelectron multiplier was used for measuring, readings were taken from digital voltmeter, data were presented in millivolts $(\mathrm{mV})$. Micrographs were obtained using Levenhuk C800 NG 8M digital camera (Levenhuk, USA).

\section{Results and Discussion.}

Amyloid is known to represent a nanotube formed as a result of aggregation of short-chain (38-42 amino acid residues) monomer fragments disfolded into $\beta$-folded conformation. Formation of $\beta$-sheet in this particular case has an energy benefit, as a physiological peptide conformation, amyloid precursor, is metastable, i.e. has some excess of energy maximum. Excessive energy shedding occurs as a result of self-folding into $\beta$-sheet, the conformation of which meets the condition of energy minimum under the given chemical medium conditions, and is therefore stable $[9,10]$ (Figure 1).

As a result of mutually parallel arrangement of filaments from 3842 amino acid residues, a regular structure is formed: a nanotube with a diameter of 10-20 nm and $1,000 \mathrm{~nm}$ long [13] capable of supramolecular interactions. It is in the state of energetic minimum, and is more stable to the action of peptidases than the initial protein. This is the cause of amyloid accumulation in the tissues. When amyloid deposits in the tissues are stained in a classical way with Congo red, light microscopy detects amyloid in the form of brick-red formations both in the cytoplasm of some cells and in the intercellular space (Figure 2 (a), (b)).

Congo red, if induced by ultraviolet light, is capable of red fluorescence in the visual range
(Figure 2 (c)). However, the quantum yield of this fluorescence is so low that it is only of theoretical interest and has not found any practical application. Congo red was established to incorporate into the ends of amyloid $\beta$-sheets only (See Figure 1). As amyloid represents the aggregates of such $\beta$-sheets forming nanotubules, which bind to connective tissue polysaccharides, it is unlikely to expect that Congo red will interact with all sites of specific bonding. Consequently, it is difficult to expect the presence of parametric characteristics of such bonding in the tissue. Nevertheless, staining with Congo red, being a sufficiently simple and highly specific method of amyloid staining, remains a clinically important standard for comparison enabling verification of specificity of other amyloid staining methods.

The second rarely used in the Russian Federation though highly specific method of amyloid detection is

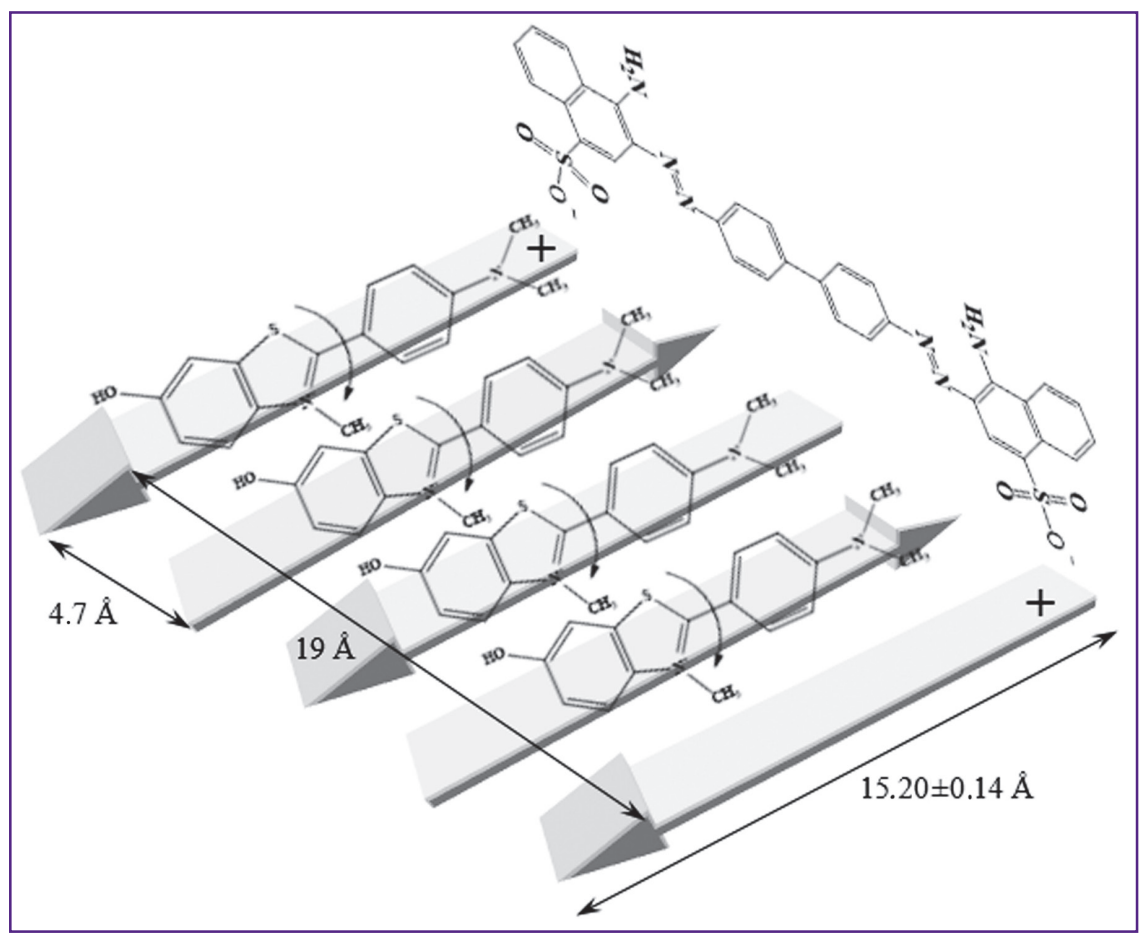

Figure 1. A model of binding Congo red [11] and thioflavin T [12] to amyloid fibrils: amyloid folds into a $\beta$-folded sheet, and every fifth protein chain has an equal $\mathrm{N}-\mathrm{C}$ direction. The length of Congo red molecule is $\approx 19 \AA$, therefore its negatively charged sulphate groups bind to positively charged residues of amino acids in the first and fifth polypeptide chains of amyloid $\beta$-folded sheet. The next molecule of the stain bonds to the third and seventh chains, and so on [11]. In the thioflavin molecule being $15.2 \pm 0.14 \AA$ in length, having the width of benzothiasol part of $6.1 \pm 0.1 \AA$, and dimethylsubstituted aniline part of $4.3 \pm 0.1 \AA$, rotation of aniline ring relative benzothiasol one takes place in a liquid medium. Rotation occurs by means of thermal energy of the environment. Incorporation of the thioflavin molecule into the amyloid $\beta$-sheet grooves is possible because of the ideal complementarity of these molecular structures. Jamming of the thioflavin molecule in the $\beta$-sheet groove stops the rotation of the parts of this molecule relative each other but does not terminate accumulation of the external energy in $\pi$-conjugated bonds. Since the conversion of the accumulated energy into the mechanical rotation in the formed supramolecule is impossible, its re-emission in the visible range takes place. The given model explains the specificity of interaction of Congo red and thioflavin $\mathrm{T}$ with amyloid fibrils and demonstrates the differences of bonding these stains to amyloid 

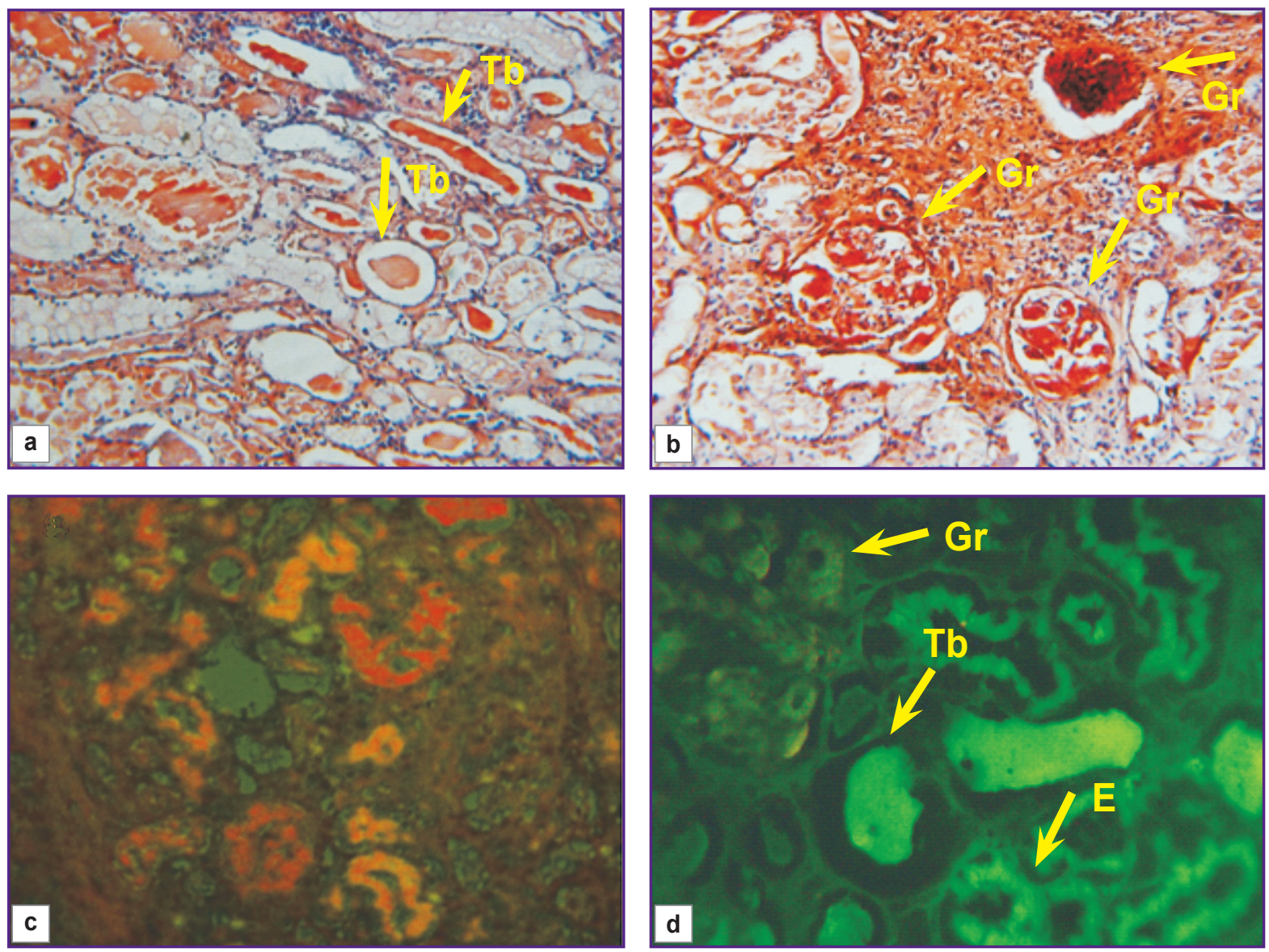

Figure 2. Staining with Congo red: light microscopy: amyloid deposits in tubules (a) and renal glomeruli (b); fluorescent microscopy (the same preparation): amyloid deposits in the tubules (c); $\times 20$. Staining with thioflavin T: amyloid deposits in the tubules (d) and glomerulus (e); $\times 40$

During fluorescent examination (c), amyloid deposits marked with Congo red look like homogeneous objects of a dark red color. Amyloid-free tissues do not fluoresce, which is typical for deparaffinated tissue sections having no autofluorescence. Gr: glomeruli, Tb: tubules, E: tubular epithelium

fluorescence with thioflavin T or S (Figure 2 (d), (e)). When stained with this dye, amyloid looks like green-brown fluorescing objects. On kidney preparations, amyloid deposits in the tubule lumens and amyloid of tubular epithelium cytoplasm are seen as bright green, practically homogeneous objects. In the vessel walls and between the capillary loops of renal glomeruli, amyloid fluoresces less intensively as a brownish tint. The amyloid-free tissue areas look dark green, almost black. Cellular nuclei are differentiated as non-luminous rounded objects.

Incorporation of thioflavin into the amyloid $\beta$-sheet structure differs from the interaction of Congo red with

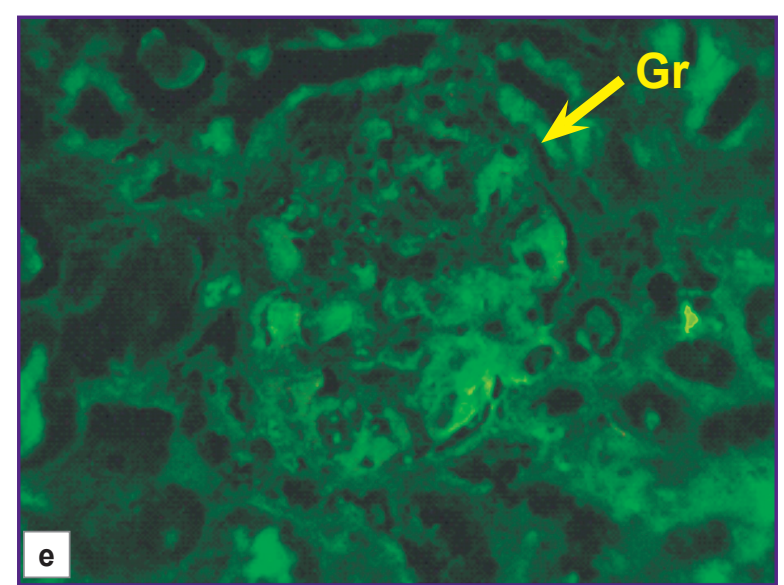

amyloid (See Figure 1). If Congo red incorporates into the end of a $\beta$-sheet, thioflavin is likely to be placed in the folds of a $\beta$-sheet (arrows on Figure 1), which stops the rotation of its dimethylaminobenzene ring relative to benzothiasole one. Fluorescence maximum of thioflavin occurs at $534 \mathrm{~nm}$. Fluorescence intensity of intact tissues is $0.014 \pm 0.003 \mathrm{mV}$, it is $0.046 \pm 0.015 \mathrm{mV}$ for amyloid-affected glomeruli, $0.053 \pm 0.012 \mathrm{mV}$ for tubular epithelium, for amyloid deposits in the tubular lumens the intensity amounts to $0.72 \pm 0.20 \mathrm{mV}$. A wide range of variations signifies that fluorescence intensity of thioflavin-marked amyloid essubstantially differs in various kidney tissue areas, and 
Figure 3. Comparison of fluorescence of dry crystals of the tested fluorophores (left scale) and those bound to amyloid on the kidney preparations (right scale). A marked bathochromic shift of fluorescence is observed when bonding to amyloid
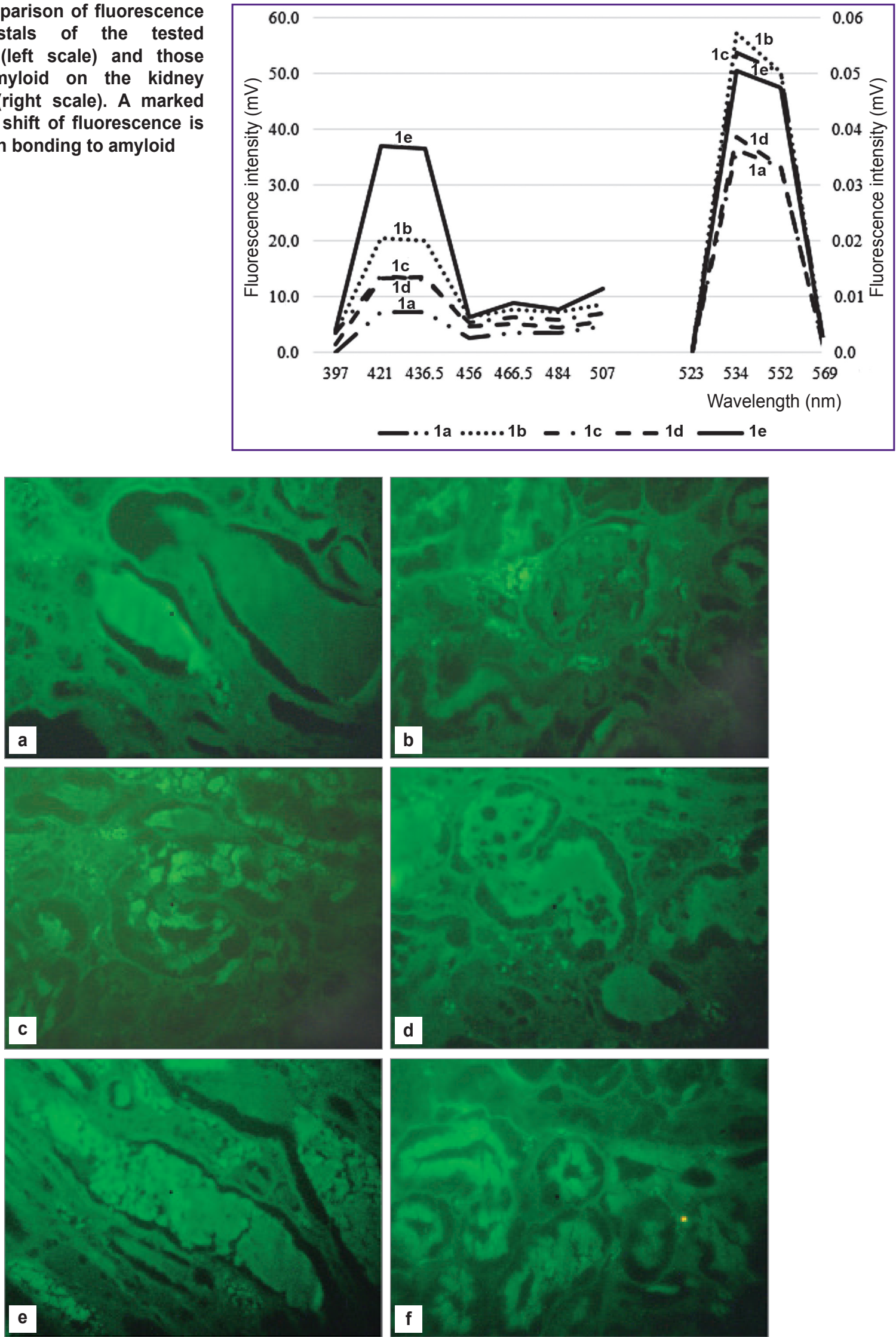

Figure 4. The results of staining of paraffin amyloid kidney sections with preparations $1 \mathrm{a}-\mathrm{e} ; \times \mathbf{4 0}$ :

preparation 1a: amyloid deposits in tubules (a) and glomeruli (b); preparations 1b (c), 1c (d), 1d (e): amyloid deposits in glomeruli; preparation 1e: amyloid deposits in tubules (e), (f) 
Table 2

Fluorescence intensity of the tested preparations 1a-e (mV)

\begin{tabular}{lccccc}
\hline \multicolumn{1}{c}{ Object } & \multicolumn{5}{c}{ Preparations } \\
\cline { 2 - 6 } & 1a & 1b & 1c & $1 \mathrm{~d}$ & $1 \mathrm{e}$ \\
\hline Glomeruli & $0.028 \pm 0.003$ & $0.038 \pm 0.004$ & $0.044 \pm 0.014$ & $0.029 \pm 0.004$ & $0.041 \pm 0.009$ \\
\hline Deposits & $0.038 \pm 0.006$ & $0.065 \pm 0.020$ & $0.057 \pm 0.004$ & $0.037 \pm 0.016$ & $0.051 \pm 0.013$ \\
\hline Tubular epithelium & $0.044 \pm 0.015$ & $0.068 \pm 0.008$ & $0.060 \pm 0.006$ & $0.047 \pm 0.007$ & $0.060 \pm 0.010$ \\
\hline
\end{tabular}

this may be the evidence of concentration dependence. Comparison of the structures of the compounds $1 \mathrm{a}-\mathrm{e}$ synthesized by us and that of thioflavin T (See Figure 1) shows that they are very similar. In contrast to thioflavin, where the methyl group performs the function of an "anchor" for nitrogen of the benzothiasole ring, in our compounds this role is played by a methyl aldehyde group.

In the tested preparations 1a-e in a dry crystal form, fluorescence maximum was observed in the range of 421.0-436.5 (Figure 3).

FEU-39 did not register any fluorescence in the alcohol or water-alcohol solutions of these substances at concentrations from 0.75 to $1.5 \%$. When the sections of amyloid kidney were treated with preparations $1(\mathrm{a}-\mathrm{e})$, intensive fluorescence was observed with the maximum in the area of $534 \mathrm{~nm}$, i.e. binding of these substances to amyloid deposits is accompanied by a pronounced bathochromic shift (Figure 4).

Less intensive fluorescence was found in glomeruli with a well detectable parietal layer of glomerular capsule and dark green amyloid deposits located between the glomerular loops, tubular epithelium and arteriole endothelium. The detected fluorescence was uniformly distributed in the cell cytoplasm. The cellular nuclei looked like dark non-fluorescing oval objects.

The intensity of the tested preparation fluorescence in the kidney structures (Table 2) did not differ significantly, which is explained by the similarity of their chemical structure.

All preparations 1a-e are supposed to have a low toxicity, since previous investigation of acute toxicity of azatricyclo-dec-enes [6] allowed this group of compounds to be referred to toxicity class IV.

Conclusion. The tested preparations 1a-e dissolved in a water-alcohol medium at $\mathrm{pH}>7$ display the properties selective to fluorophore amyloid. Binding of preparations 1a-e to amyloid deposits is accompanied by a sharp increase of fluorescence intensity compared to their water-alcohol solutions, and a marked bathochromic shift. This fact allows us to assert that the mechanism of realizing the fluorescent properties of novel examined substances is implemented in a way similar to thioflavin T. Taking into consideration low prices of the raw material necessary for preparations 1a-e synthesis, simplicity and low cost of the synthesis itself, a high quantum yield, easiness of preparation staining, as well as probable low toxicity, it can be stated that all proposed substances have a good perspective of being used as new fluorophores for amyloid detection.

Study Funding. The work was supported by the grant of the Foundation for promoting the development of small-scale enterprises, agreement 0004043.

Conflicts of Interest. The authors have no conflicts of interest to disclose.

\section{References}

1. Sulatskaya A.I. Vzaimodeystvie tioflavina Ts amiloidnymi fibrillami: mekhanizm vstraivaniya, parametry svyazyvaniya, izmenenie fotofizicheskikh kharakteristik krasitelya. Avtoref. dis. ... dokt. biol. nauk [Interaction of thioflavin $\mathrm{T}$ with amyloid fibrils: mechanism of incorporation, parameters of binding, alteration of photochemical characteristics of the stain. DSc Thesis]. Saint Petersburg; 2013.

2. Kuznetsova I.M. Mekhanizmy vozniknoveniya i svoystva promezhutochnykh, nepravil'no svernutykh i agregirovannykh form belkov. Avtoref. dis. ... dokt. biol. nauk [Mechanisms of formation and properties of intermediate, misfolded, and aggregated forms of proteins. DSc Thesis]. Saint Petersburg; 2006.

3. Liu R., Su R., Qi W., He Z. Photo-induced inhibition of insulin amyloid fibrillation on online laser measurement. Biochem Biophys Res Commun 2011; 409(2): 229-234, https://doi.org/10.1016/j.bbrc.2011.04.132.

4. Van J., Klank U.Eh., Matis Ch.Eh. ml. Proizvodnye tioflavina, svyazyvayushchie amiloid, sposob obnaruzheniya in vivo otlozheniy amiloida $i$ sposob raspoznavaniya bolezni Al'tsgeymera [Amyloid-binding thioflavin derivatives, method of in vivo detection of amyloid deposit and method of diagnosis of Alzheimer's disease]. Patent RU 2324686 C2. 2008.

5. Freshtl' V., Srinivasachari N., Lomann S., LopesDeber M.-P., Mus A., Pil'gren-Bosh M. Novye soedineniya dlya lecheniya zabolevaniy, svyazannykh s amiloidom ili amiloidpodobnymi belkami [New compounds for treating amyloid or amyloid-like protein associated diseases]. Patent RU 2469026 C2. 2012.

6. Kozlov V.A., Mitrasov Yu.N., Kondrat'eva O.V., Gordeeva I.V., Polyakova O.B., Gruzdev S.E., Fedorova M.L., Borzova A.A. Ostraya toksichnost' 4-aza-1-gidroksimetil-10oksa-3,5-diokso-4-feniltritsiklo[5,2,11,7,02,6]dets-8-ena. V kn.: Materialy 8-y mezhdunarodnoy nauchnoy shkoly "Nauka i innovatsii - 2013" [Acute toxicity of 4-aza-1-hydroxymethyl10-oxa-3,5-dioxo-4-phenyltricyclo [5,2,11,7,02,6]dec-8-ena. In: Materials of VIII International Scientific School "Science and Innovations - 2013"]. Yoshkar-Ola; 2013; p. 264-265.

7. Kozlov V.A., Sapozhnikov S.P., Mitrasov Yu.N., 
Avruyskaya A.A., Karyshev P.B., Sheptukhina A.I., Nikolaeva O.V. Sposob fluorestsentnogo gistologicheskogo vyyavleniya amiloida [Method of fluorescent histological detection of amyloid]. Patent RU 2611408. 2017.

8. Burns J., Pennock C.A., Stoward P.J. The specificity of the staining of amyloid deposits with thioflavine T. J Pathol Bacteriol 1967; 94(2): 337-344, https://doi.org/10.1002/ path.1700940211.

9. Knowles T.P.J., Vendruscolo M., Dobson C.M. The amyloid state and its association with protein misfolding diseases. Nat Rev Mol Cell Biol 2014; 15(6): 384-396, https:// doi.org/10.1038/nrm3810.

10. Krebs M.R., Bromley E.H., Donald A.M. The binding of thioflavin-T to amyloid fibrils: localisation and implications. J Struct Biol 2005; 149(1): 30-37, https://doi.org/10.1016/j. jsb.2004.08.002.
11. Klunk W.E., Pettegrew J.W., Abraham D.J. Quantitative evaluation of congo red binding to amyloid-like proteins with a beta-pleated sheet conformation. J Histochem Cytochem 1989; 37(8): 1273-1281, https://doi.org/10.1177/37.8.2666510.

12. Held P., Becker K. Analysis of a-synuclein fibril formation in vitro. Using fluorescence to monitor protein aggregation in microplates. Biotek; 2014. URL: http://www. biotek.com/resources/articles/analysis-of-synuclein-fibrilformation-in-vitro.html.

13. Baldwin A.J., Knowles T.P., Tartaglia G.G., Fitzpatrick A.W., Devlin G.L., Shammas S.L., Waudby C.A., Mossuto M.F., Meehan S., Gras S.L., Christodoulou J., Anthony-Cahill S.J., Barker P.D., Vendruscolo M., Dobson C.M. Metastability of native proteins and the phenomenon of amyloid formation. J Am Chem Soc 2011; 133(36): 14160-14163, https://doi.org/10.1021/ja2017703. 